\title{
Article \\ Effect of Cold Rolling and Annealing on the Microstructure and Texture of Erbium Metal
}

\author{
Shiying Chen 1,2,3, Xiaowei Zhang 1,2,3,*, Zongan Li 1,2,3, Shuang Wang 1,2, Yixuan Wang 1,2,3, Jinying Li 1,2,3, \\ Daogao Wu ${ }^{1,2}$, Zhiqiang Wang ${ }^{1,2}$, Dehong Chen ${ }^{1,2}$, Wenli Lu ${ }^{1,2}$, Ning Mao ${ }^{1,2}$, Wensheng Yang ${ }^{1,2}$ \\ and Minglei $\mathrm{Xu}{ }^{1,2}$
}

check for updates

Citation: Chen, S.; Zhang, X.; Li, Z.; Wang, S.; Wang, Y.; Li, J.; Wu, D.; Wang, Z.; Chen, D.; Lu, W.; et al. Effect of Cold Rolling and Annealing on the Microstructure and Texture of Erbium Metal. Materials 2022, 15, 1370. https://doi.org/10.3390/ ma15041370

Academic Editors:

Szymon Wojciechowski and Pavel Lukáč

Received: 16 December 2021

Accepted: 28 January 2022

Published: 12 February 2022

Publisher's Note: MDPI stays neutral with regard to jurisdictional claims in published maps and institutional affiliations.

Copyright: () 2022 by the authors. Licensee MDPI, Basel, Switzerland. This article is an open access article distributed under the terms and conditions of the Creative Commons Attribution (CC BY) license (https:// creativecommons.org/licenses/by/ $4.0 /)$.
1 National Engineering Research Center for Rare Earth, GRINM Group Co., Ltd., Beijing 100088, China; chenshiying1023@163.com (S.C.); zonganli@126.com (Z.L.); Wangshuang_WJ@163.com (S.W.); wangyx8945@163.com (Y.W.); 13278885733@163.com (J.L.); daodao173@163.com (D.W.); wzq97122@126.com (Z.W.); chen-dh@126.com (D.C.); lonely1304178568@163.com (W.L.); maoning234@163.com (N.M.); yws3179608@163.com (W.Y.); xml783235495@163.com (M.X.)

2 GRIREM Advanced Materials Co., Ltd., Beijing 100088, China

3 General Research Institute for Nonferrous Metals, Beijing 100088, China

* Correspondence: 0420295@163.com

\begin{abstract}
Erbium metal with purity $\geq 99 \%$ was cold rolled to $30 \%, 40 \%, 50 \%$, and $60 \%$ deformations and the Er metal of $60 \%$ deformation was annealed at different temperatures for $1 \mathrm{~h}$. The effect of cold rolling deformation and annealing on the microstructure and texture evolution of Er metal was investigated by XRD, EBSD, Microhardness tester, and OM. P is the orientation index, which is used to judge the preferred orientation. The research results showed that grains were broken and refined gradually with increasing deformation, the average grain size was $3.37 \mu \mathrm{m}$, and the orientation distribution was uniform for $60 \%$ deformation; deformation twins appeared in the grain when the deformation was less than $40 \%$, which contributed to the generation of (0001) plane orientation. Comparing with the initial state, the (0110) plane orientation gradually weakened and the $(11 \overline{10})$ plane orientation had a trend of further strengthening with the increasing deformation; the (1210) plane orientation remained unchanged, but there was a gradual weakening trend when the deformation was greater than 50\%. For $60 \%$ deformation of Er metal, the deformed microstructure was replaced by fine equiaxed grains with the increasing annealing temperature, and the highperformance Er metal with fine and uniform equiaxed grains can be obtained under annealing at $740{ }^{\circ} \mathrm{C}$ for $1 \mathrm{~h}$.
\end{abstract}

Keywords: erbium target; cold rolling; annealing; microstructure; crystal orientation

\section{Introduction}

In recent years, rare earth oxide films have received widespread attention due to their high dielectric constant, large band gap width, and good thermal stability [1]. $\mathrm{Er}_{2} \mathrm{O}_{3}$ film is an ideal candidate for high dielectric materials and has a strong competitiveness in the new generation of metal oxide semiconductor field effect transistor (MOSFET) gate dielectrics [2-4]. Moreover, $\mathrm{Er}_{2} \mathrm{O}_{3}$ thin film can be applied to optical devices, tritium permeation barrier (TPB), and hydrogen storage [5,6]. Furthermore, erbium (Er) thin film is an ideal neutron generator for tritium target material in nuclear industry [7-9]. Erbium target is the key raw material of erbium oxide film and erbium film, and its quality directly affects the functional characteristics of the films. Therefore, it is necessary to obtain high-quality sputtering Er target with high purity, fine grain, uniform structure, and preferred orientation.

However, as-cast Er metal can't satisfy the specifications of industrial sputtering targets, the grains usually need to be refined and crystal orientation should be optimized by 
rolling and annealing. Most rare earth metals have hexagonal close-packed (HCP) structure and fewer slip systems; therefore, the plastic deformation is very difficult because the rolling deformation process can easily cause stress concentration and lead to cracking $[10,11]$. There is a lot of research involving magnesium [12-14] and magnesium alloy $[15,16]$, and titanium $[17,18]$ and titanium alloy [19-21], but there are few studies on the deformation of rare earth metal. Huang P. [22] studied the effects of annealing temperatures on the hardness and microstructure of high-purity metal scandium metal after hot forging, and obtained the optimum annealing process of $725{ }^{\circ} \mathrm{C} \times 0.5 \mathrm{~h}$. Wang S. [23] studied the effect of annealing temperature on the microstructure of high-purity Er target under $80 \%$ deformation after hot rolling and obtained the optimum annealing process of $570{ }^{\circ} \mathrm{C}$ $\times 1 \mathrm{~h}$. However, hot deformation process can easily lead to target oxidation, serious loss of raw materials, and worse surface quality. Compared with hot deformation, cold deformation has the advantages of a controllable microstructure, less loss, and precision deformation. S. Taskaev [24-27] has studied the effects of cold rolling deformation and annealing temperature on the specific heat, magnetic and magnetocaloric properties of gadolinium, terbium, and dysprosium. However, the effect of cold rolling and annealing on the evolution of the microstructure and texture of Er metal with HCP structure has not been studied.

In the present study, the cold rolling and annealing of Er metal has been performed. The influence of cold rolling deformation and heat treatment temperature on the microstructure, texture, and hardness of the Er metal target were studied, and the deformation mechanism and optimum annealing process were obtained.

\section{Experimental}

The commercially pure Er metal (99 wt.\%) samples with dimensions of $50 \mathrm{~mm} \times$ $25 \mathrm{~mm} \times 12 \mathrm{~mm}$ were cold rolled by total deformation of $30 \%, 40 \%, 50 \%$, and $60 \%$, with $0.3 \mathrm{~mm}$ reduction during each pass (when the deformation exceeds 60\%, Er samples started to be fractured), and the stress relief annealing was at $520^{\circ} \mathrm{C}$ for $1 \mathrm{~h}$ when the deformation was increased by $10 \%$. The rolling was performed at a speed of $150 \mathrm{r} / \mathrm{min}$ by means of a two-high mill rolling machine (Wuxi Xingxiang Metallurgical Machinery Factory, Jiangsu, China) with a roll diameter of $500 \mathrm{~mm}$. The $60 \%$ cold-rolled Er samples were vacuum annealed at $460{ }^{\circ} \mathrm{C}, 500{ }^{\circ} \mathrm{C}, 540{ }^{\circ} \mathrm{C}, 620{ }^{\circ} \mathrm{C}, 660^{\circ} \mathrm{C}, 700{ }^{\circ} \mathrm{C}, 740{ }^{\circ} \mathrm{C}, 780{ }^{\circ} \mathrm{C}$, and $820{ }^{\circ} \mathrm{C}$ for $1 \mathrm{~h}$ in a tube furnace with the vacuum degree less than $10^{-1} \mathrm{~Pa}$ (The annealing temperature was chosen according to the recrystallize(ation starting temperature of $460{ }^{\circ} \mathrm{C} \sim 520^{\circ} \mathrm{C}$ approximately), then the samples were cooled down naturally with the furnace. The schematic diagram of the cold rolling process was shown in Figure 1.

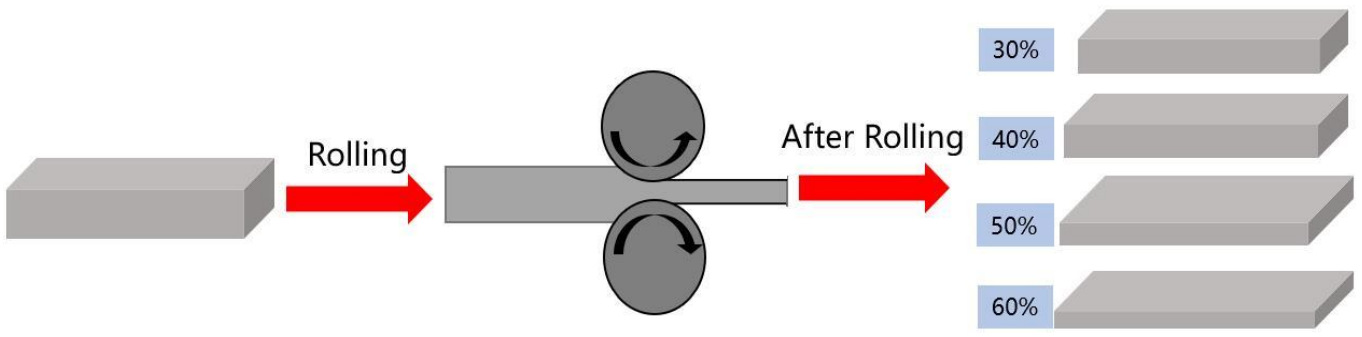

Figure 1. Schematic diagram of cold rolling process of Er metal.

The samples were surface-grinded with silicon carbide sandpaper from 200 mesh to 5000 mesh and mechanically polished with $0.5 \mu \mathrm{m}$ diamond spray polishing agent, samples for EBSD measurements need to be further polished with argon ion. The microstructure, grain orientation, grain boundary distribution, and grain size on the rolling direction (RD) and normal direction (ND) plane at the mid-width of the sample were observed by the MM-6 optical microscope (OM, produced by Shanghai Optical Instrument Factory No.6, Shanghai, China) and Electron Backscattered Diffraction (EBSD). EBSD analysis was carried out on using ZEISS-Sigma500 scanning electron microscope equipped (Zeiss Germany, 
Jena, Germany) with an Oxford-symmetry accessory. The grain orientation on the RD-ND plane was analyzed by Philips PANalytical X-ray Diffraction (XRD) unit (PW3373, Almelo, The Netherlands) with $\mathrm{Cu}-\mathrm{K} \alpha$ radiation. The hardness (HV0.3) was tested by an HVS1000A Vickers microhardness tester(Huayin Test Instrument Co. LTD, Laizhou, China), which indirectly reflected the recrystallization during the annealing process; the load of the microhardness tester was $3 \mathrm{~N}$ and the load time was 10s. The RD-ND surface of Er samples was shown in Figure 2.

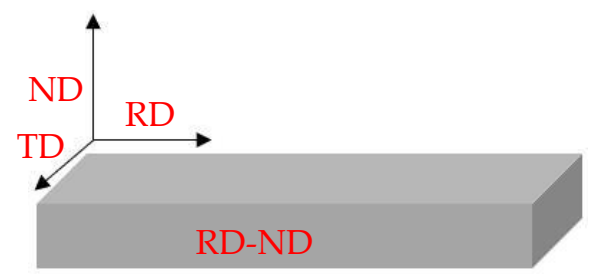

Figure 2. RD-ND surface of Er samples.

\section{Results and Discussion}

\subsection{Starting Material of Er Metal}

Figure 3 shows the microstructure, inverse pole figure (IPF) map, and grain size distribution of the initial as-cast Er metal. In the Figure 3a, the grains of initial as-cast metal are mainly irregular equiaxed crystals and the grain size distribution is not uniform; some fine crystal grains are observed around the coarse equiaxed crystals, as shown in the circles of Figure 3a. Rare earth metal is prone to oxidation during polishing and corrosion treatment, therefore, there are a large number of black spots at the grain boundaries and inside the grains, which is identified by red arrows in Figure 3a. Figure $3 b, c$ are the IPF map and grain size distribution tested by EBSD on the RD-ND plane, respectively, which show that the grain size distribution in the initial Er samples is not uniform, the size of large grains is larger than $200 \mu \mathrm{m}$, and that it is smaller than $50 \mu \mathrm{m}$ for some fine grains. Meanwhile, the grain distribution is disordered and many fine grains are observed in the large grains. It can be observed from Figure $3 b$ that the crystal orientation of the initial as-cast Er metal mainly includes $(\overline{12} \overline{10})$ and $(01 \overline{1} 0)$ plane on the RD-ND plane.
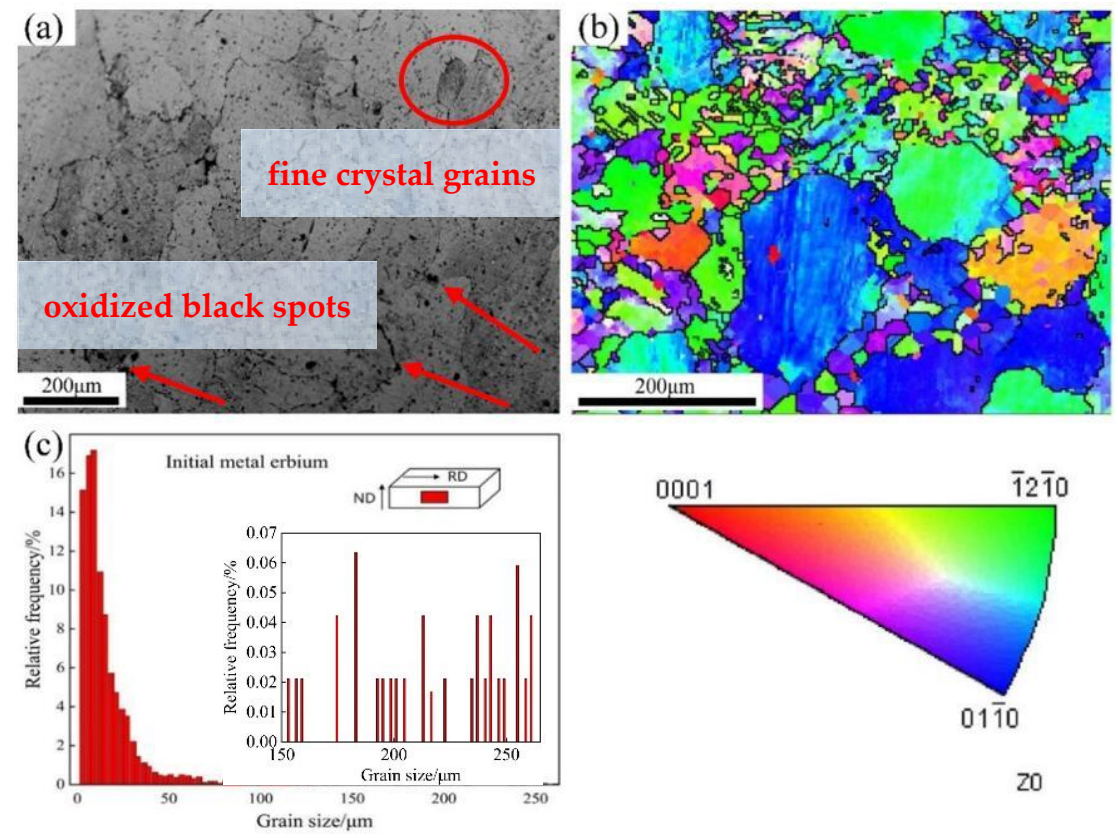

Figure 3. Microstructure, inverse pole figure (IPF) map and grain distribution of the initial as-cast metal: (a) microstructure; (b) crystal orientation; and (c) grain size distribution. 


\subsection{The Influence of Cold Rolling Deformation on the Microstructure and Texture of Er Metal}

Figure 4 shows the IPF map of cold rolling Er samples. In Figure 4a, when the deformation comes to $30 \%$, compared with the initial as-cast state, most of the grains are broken and refined, some twins are formed inside the grains (as identified by the yellow arrows), but there are lots of large deformed grains; furthermore, the crystal orientations mainly include (1210) and (0110). When the deformation reaches to $40 \%$, as shown in Figure $3 b$, massive structure disappears and the grains are further refined, there is also a small part of twins formed (as identified by the yellow arrows), and the crystal orientations mainly include $(\overline{12} \overline{10}),(01 \overline{10})$, and (0001), which indicates that the formation of twins contributes to the (0001) orientation. When the deformation increases to $50 \%$, the grains are a bit further refined, twins disappear, and the crystal orientation distribution is uniform; the reason for the twins' disappearance is that the slip is activated under the heat conditions in which the deformation temperature increases, which is an important role in the release of stress concentration in plastic deformation and becomes the main mechanism for plastic deformation in the larger cold rolling deformation process. The result indicates that the deformation mechanism is twinning and slip synergistic at the beginning stage of cold rolling and then transforms to slip-based at large than $40 \%$ cold rolling deformation. The similar transformation of deformation mechanism has been observed in cold rolled titanium by Ren Y. et al. [28]. When the deformation increases to $60 \%$, the grains are completely destroyed and dominated by fine deformed structures, the grain boundaries increase correspondingly, there are no new twins, and the crystal orientation distribution is more uniform, but some small crystal nuclei are formed inside the grain, as shown by the circle in Figure 4d.
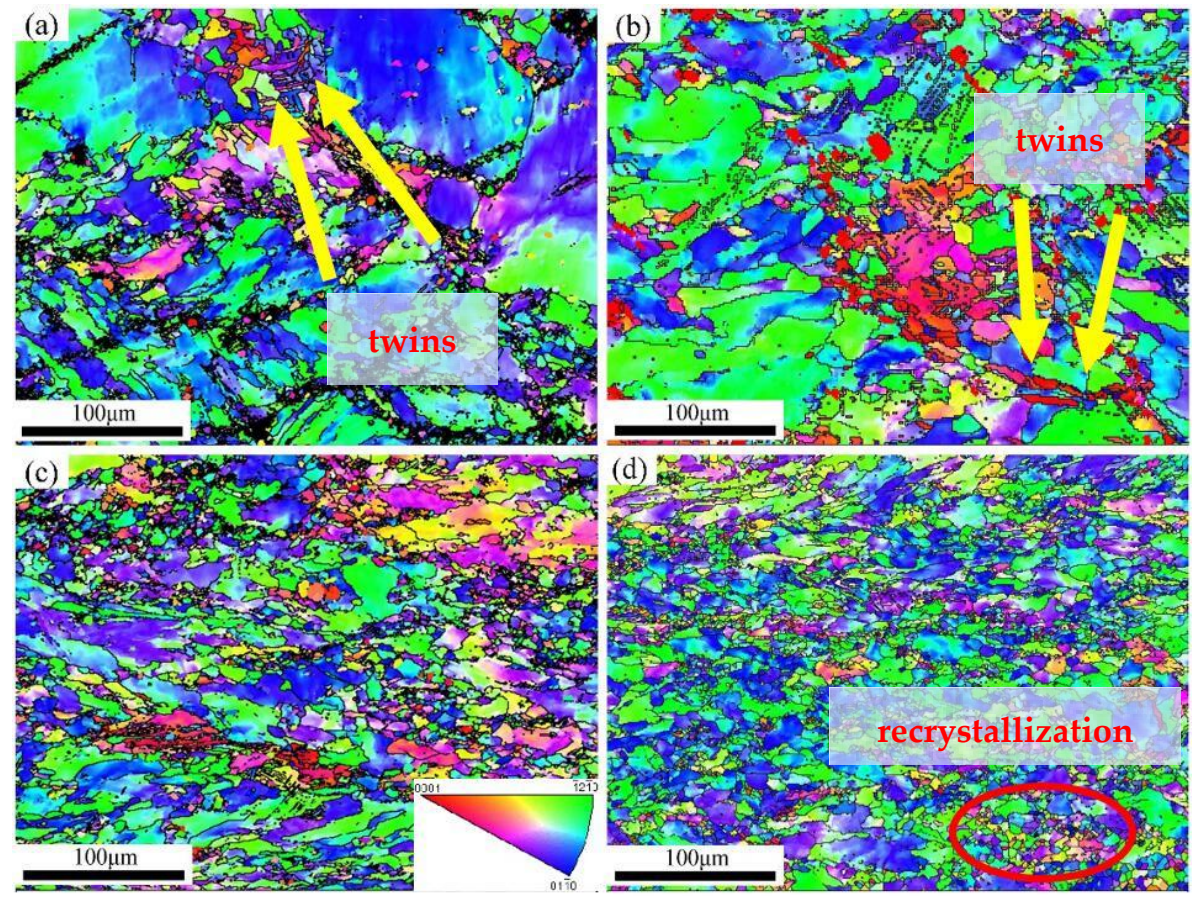

Figure 4. EBSD IPF maps during different cold rolling deformation: (a) 30\%, (b) 40\%, (c) 50\%, and (d) $60 \%$.

Figure 5 is the relationship curve between deformation and average grain size. The average grain size of Er decreases from $6.87 \mu \mathrm{m}$ at $30 \%$ deformation to $3.87 \mu \mathrm{m}$ at $40 \%$ deformation rapidly. When the deformation is greater than $40 \%$, the average grain size slowly decreases from $3.87 \mu \mathrm{m}$ at $40 \%$ deformation to $3.37 \mu \mathrm{m}$ at $60 \%$ deformation, combined with 
the fine microstructure in Figure $4 \mathrm{~d}$, which indicates that grains are almost broken and refined completely after $60 \%$ cold rolling deformation.

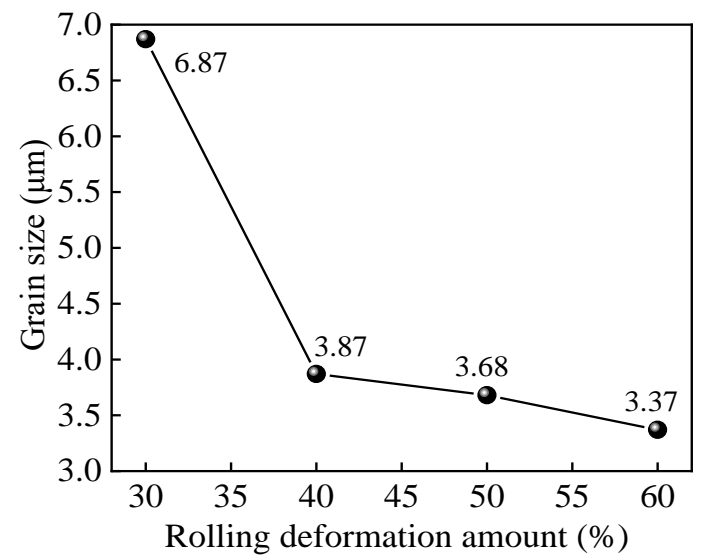

Figure 5. The relationship curve between deformation and average grain size.

Figure 6 and Table 1 show the distribution of the grain characteristics of the Er after cold rolled deformations. It is observed that the deformation area accounts for $88.28 \%$, and the recrystallized grains area accounts for $1.79 \%$ when the deformation is $30 \%$. After rolling at $40 \%$ deformation, the deformation area increases to $96.21 \%$. Moreover, when the deformation increases to $50 \%$, the deformation area is $94.60 \%$, which is approximately the same as that of $40 \%$ deformation. However, when rolling deformation increases to $60 \%$, the deformation area drops to $85.09 \%$ and the recrystallized area increases to $6.60 \%$. Therefore, it is concluded that the degree of deformation first increases, then stabilizes, and then gradually decreases, and the degree of deformation gradually decreases because the freshly recrystallized grains replace the original deformed microstructure, which is consistent with the results in Figure 4.
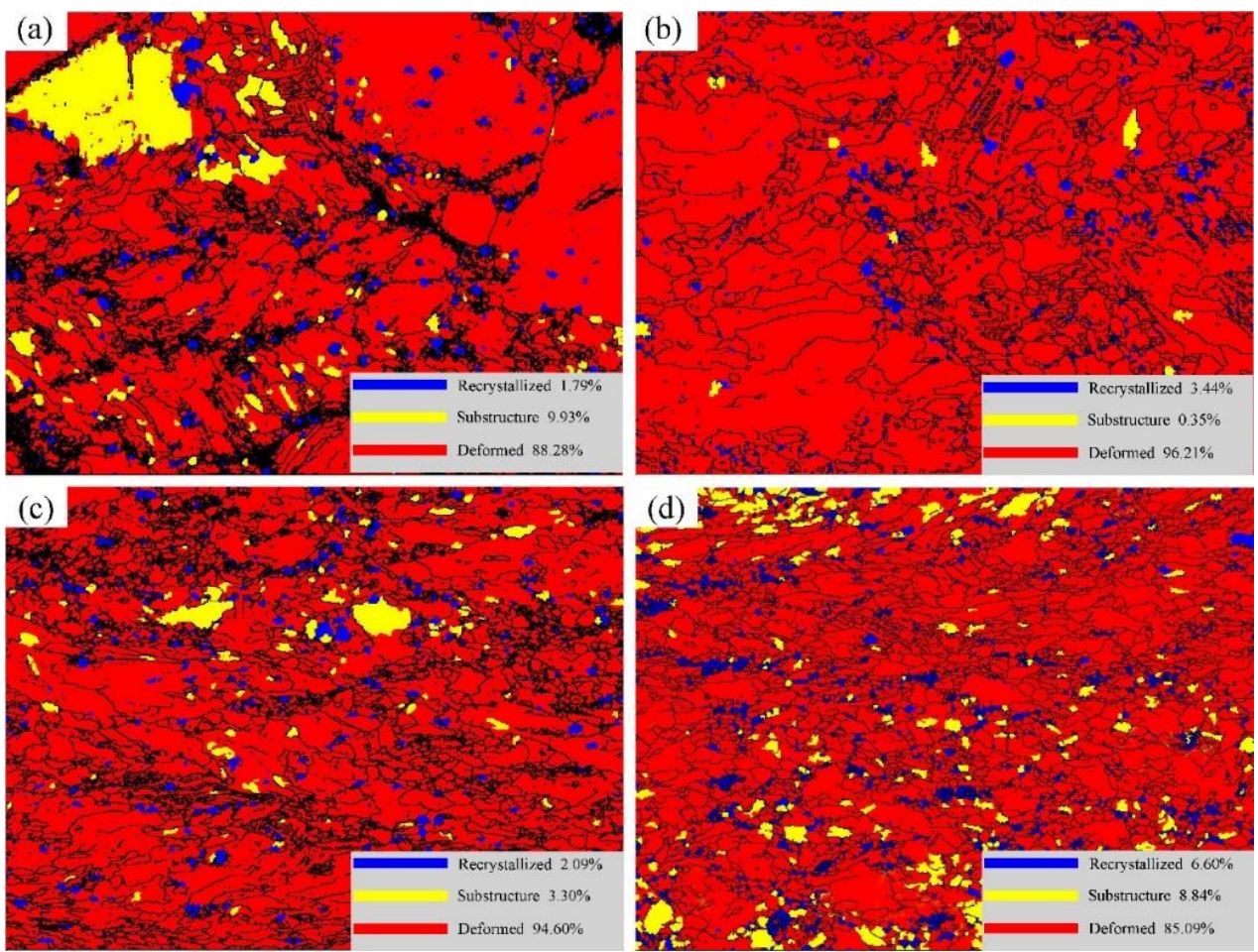

Figure 6. Grain distribution characteristics of Er metal with various cold rolling deformations: (a) 30\%, (b) $40 \%$, (c) $50 \%$, and (d) $60 \%$. 
Table 1. Proportion of recrystallization area and deformation area of Er metal with various cold rolling deformation.

\begin{tabular}{cccc}
\hline Deformation & Recrystallized (\%) & Substructure (\%) & Deformed (\%) \\
\hline $30 \%$ & 1.79 & 9.93 & 88.28 \\
$40 \%$ & 3.44 & 0.35 & 96.21 \\
$50 \%$ & 2.09 & 3.30 & 94.60 \\
$60 \%$ & 6.60 & 8.84 & 85.09 \\
\hline
\end{tabular}

Figure 7 is the misorientation distribution of Er metal. It is observed that most of the misorientation angles are high-angle grain boundaries $\left(\theta>15^{\circ}\right)$, and there are few low-angle grain boundaries $\left(0^{\circ}<\theta<15^{\circ}\right)$ in the initial as-cast metal. The high-angle grain boundaries gradually decrease and the low-angle grain boundaries gradually increase with deformation increasing. After 50\% cold-rolled deformation, the content of low-angle grain boundaries increases to $83.25 \%$. When the deformation increases to $60 \%$, the low-angle grain boundaries reduce to $79.34 \%$. A greater low-angle grain boundary content reflects that there will be greater degree of deformation and dislocation density $[29,30]$. Therefore, the results show that the increase trend of deformation degree and dislocation density is stable after $40 \%$ cold-rolled deformation. When the deformation reaches to $60 \%$, the lowangle grain boundaries decrease, which indicates that partial recovery and recrystallization have occurred. This is consistent with the results of Figures 4 and 6.
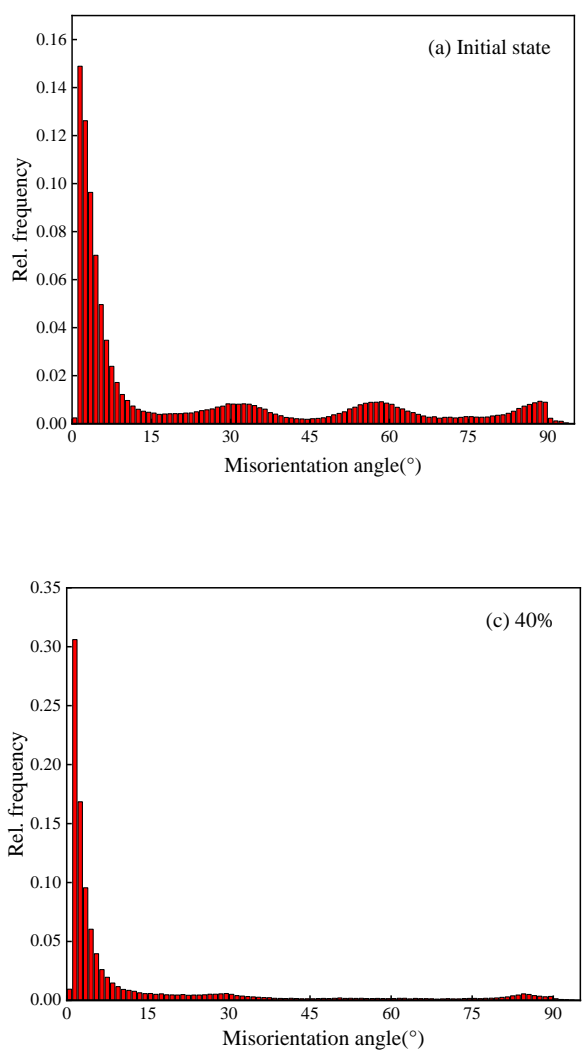
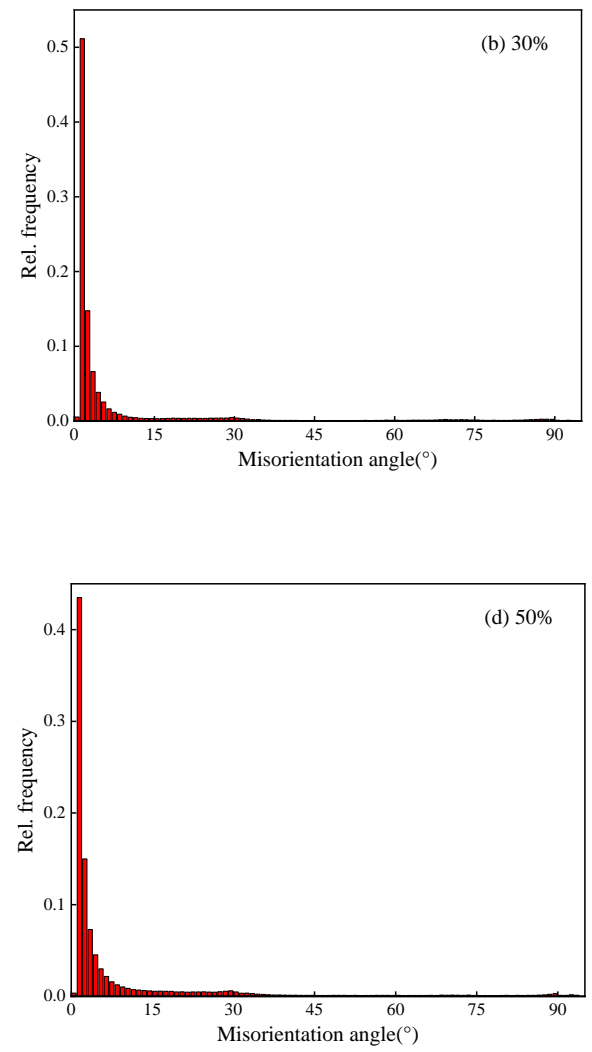

Figure 7. Cont. 


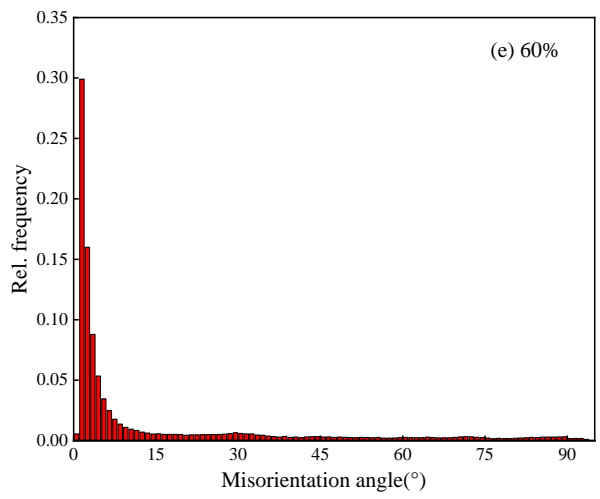

Figure 7. Misorientation distribution of Er metal with various cold rolling deformation: (a) initial state, (b) $30 \%$, (c) $40 \%$, (d) $50 \%$, and (e) $60 \%$.

In order to further analyze the texture evolution in the cold rolling process, the crystal orientation on RD-ND plane of Er metal is analyzed by XRD. The results are shown in Figure 8 , in which it can be clearly observed that the intensity of the $(01 \overline{10}),(\overline{12} \overline{1} 0)$, and (1110) change with the increasing deformation. However, it can't directly reflect the change trend of the crystal orientation relative to the initial as-cast state. Therefore, the orientation index $P$ is introduced, calculated as following:

$$
P=\frac{R}{R_{0}}
$$

where $R$ is intensity ratio of the two characteristic peaks of the sample, and $R_{0}$ is intensity ratio of the two characteristic peaks of the sample with no preferred orientation, which is used as a criterion for orientation. $R$ can be expressed as Equation (2):

$$
R=\frac{I_{\left(\mathrm{H}_{1} \mathrm{~K}_{1} \mathrm{~L}_{1}\right)}}{I_{\left(\mathrm{H}_{1}^{\prime} \mathrm{K}^{\prime}{ }_{1} \mathrm{~L}_{1}^{\prime}\right)}}
$$

where $\mathrm{I}_{\left(\mathrm{H}_{1} \mathrm{~K}_{1} \mathrm{~L}_{1}\right)}$ and $\mathrm{I}_{\left(\mathrm{H}_{1}^{\prime} \mathrm{K}_{1} \mathrm{~L}_{1}\right)}$ are the diffraction intensity of the $\left(\mathrm{H}_{1} \mathrm{~K}_{1} \mathrm{~L}_{1}\right)$ and $\left(\mathrm{H}_{1}^{\prime} \mathrm{K}_{1}^{\prime} \mathrm{L}_{1}^{\prime}\right)$, respectively, with preferred orientation. $R_{0}$ is calculated as following:

$$
R_{0}=\frac{I_{\left(\mathrm{H}_{0} \mathrm{~K}_{0} \mathrm{~L}_{0}\right)}}{I_{\left(\mathrm{H}_{0}^{\prime} \mathrm{K}_{0}^{\prime} \mathrm{L}_{0}^{\prime}\right)}}
$$

where $I_{\left(\mathrm{H}_{0} \mathrm{~K}_{0} \mathrm{~L}_{0}\right)}$ and $I_{\left(\mathrm{H}_{0}^{\prime} \mathrm{K}_{0}^{\prime} \mathrm{L}_{0}^{\prime}\right)}$ are the diffraction intensity of the $\left(\mathrm{H}_{0} \mathrm{~K}_{0} \mathrm{~L}_{0}\right)$ and $\left(\mathrm{H}_{0}^{\prime} \mathrm{K}_{0}^{\prime} \mathrm{L}_{0}^{\prime}\right)$, respectively, without preferred orientation. When the orientation index $\mathrm{P}$ equals 1 , it indicates that there is no preferred orientation, when $p$ deviates from 1 , it indicates that the preferred orientation occurs. The greater the deviation, the more obvious the preferred orientation [31-33].

In the present study, $\mathrm{I}_{0}$ is the (1132) orientation intensity value in each state, which is selected as the reference for all samples. The calculation results are shown in Figure 9 and Table 2, $\mathrm{P}(01 \overline{1} 0), \mathrm{P}(0001), \mathrm{P}(\overline{1} 2 \overline{1} 0)$, and $\mathrm{P}(11 \overline{1} 0)$ are the orientation index of $(01 \overline{1} 0)$, (0001), $(\overline{12} \overline{1} 0)$ and $(11 \overline{10})$, respectively. It is observed that the value of $\mathrm{P}(01 \overline{10})$ decreases from 1.791 at $30 \%$ deformation to 1.184 at $60 \%$ deformation, which reveals that the crystal orientation of $(01 \overline{1} 0)$ is gradually weakened with the increasing deformation. The value of $\mathrm{P}(0001)$ is greater than 1.2 when the deformation is $40 \%$ and is constant around 1 on other deformation conditions; this indicates that (0001) plane has a stronger orientation at $40 \%$ deformation, but there is no obvious preference under other cold rolling deformation. 
The value of $\mathrm{P}(1210)$ is around 1 before $40 \%$ deformation, the deviation from 1 is large when the deformation is greater than $50 \%$, but the orientation index is less than 1 at this time, which indicates that the preference orientation remains unchanged in the beginning deformation stage, and then presents a gradual weakened trend after $50 \%$ deformation. The value of $\mathrm{P}(11 \overline{10})$ is 1.552 at $30 \%$ deformation and increases to 1.771 at $60 \%$ cold rolling deformation, this indicates that the preferred orientation of the (1110) plane is obvious and there is a further enhancement trend with the deformation increases.

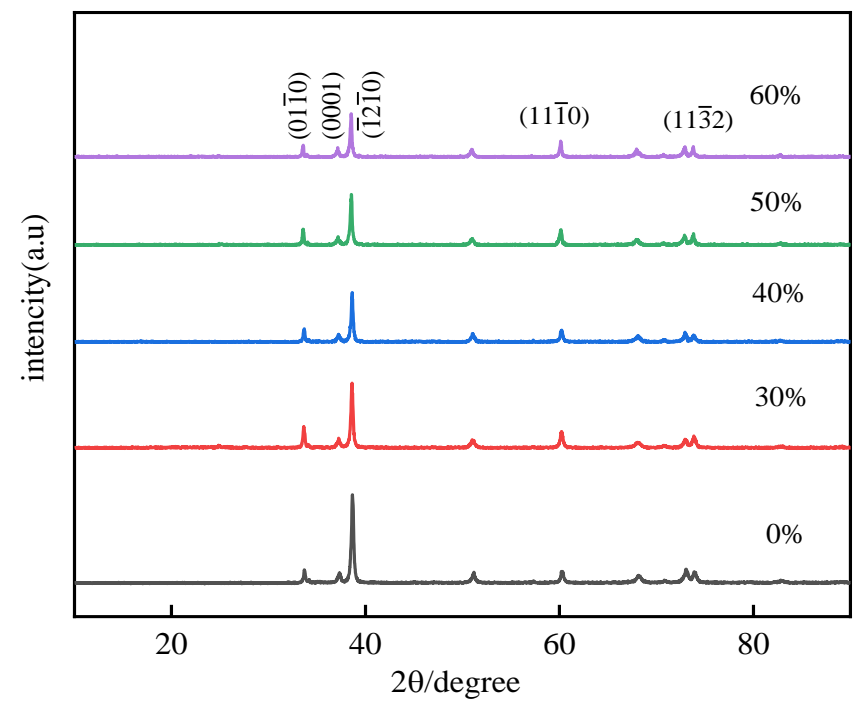

Figure 8. XRD map of Er metal with various cold rolled deformation.

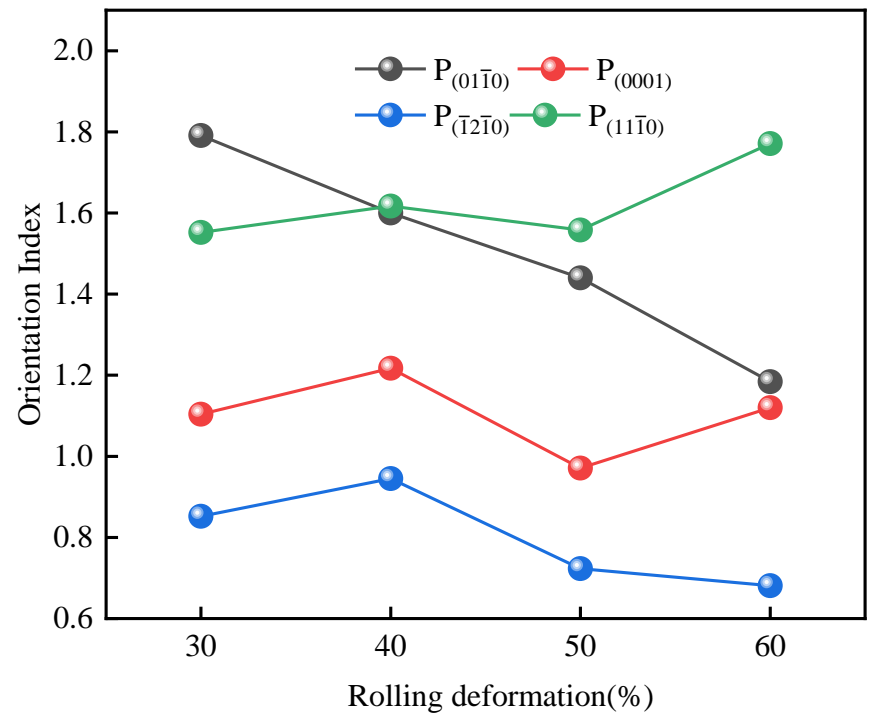

Figure 9. The relationship between the orientation index changes of Er metal with various cold rolling deformation.

Table 2. The orientation index of crystal orientation under different deformation.

\begin{tabular}{ccccc}
\hline Deformation & $\mathbf{P}(\mathbf{0 1 \mathbf { 1 0 }})$ & $\mathbf{P}(\mathbf{0 0 0 1})$ & $\mathbf{P ( \mathbf { 1 } \mathbf { 1 } \mathbf { 0 } )}$ & $\mathbf{P}(\mathbf{1 1} \overline{\mathbf{1}} \mathbf{)}$ \\
\hline $30 \%$ & 1.791 & 1.104 & 0.852 & 1.552 \\
$40 \%$ & 1.600 & 1.220 & 0.945 & 1.617 \\
$50 \%$ & 1.440 & 0.971 & 0.723 & 1.558 \\
$60 \%$ & 1.184 & 1.120 & 0.681 & 1.771 \\
\hline
\end{tabular}




\subsection{The Effect of Annealing Temperature on Microstructure and Microhardness of Er Metal}

When the deformation increases to $60 \%$, the sample is dominated mainly by fine deformed structure; therefore, the Er metal with $60 \%$ deformation is selected to be annealed at $460{ }^{\circ} \mathrm{C}-820{ }^{\circ} \mathrm{C}$ for $1 \mathrm{~h}$, and the microstructure after annealing treatment is shown in Figure 10. When the heat treatment temperature is $460{ }^{\circ} \mathrm{C}$, a small amount of fine recrystallized crystal nuclei is formed, and the grain size distribution is nonuniform, but there is still a lot of deformed structure as shown in Figure 10a. When the temperature increases to $500{ }^{\circ} \mathrm{C}$, there is obvious recrystallization and a large number of small, equiaxed grains. When the annealing temperature increases from $540{ }^{\circ} \mathrm{C}$ to $700{ }^{\circ} \mathrm{C}$, the recrystallized grains grow rapidly, and the deformed structure disappears gradually so that the number of equiaxed crystals increase continuously and the uniformity of grain distribution improves constantly, but there are still some fine and uneven recrystallized grains. In Figure 10g, the deformed grains have been completely replaced by the uniform and fine equiaxed recrystallized grains, which indicates that the recrystallization process has finished when the temperature comes to $740{ }^{\circ} \mathrm{C}$. When the temperature further increases to $780{ }^{\circ} \mathrm{C}$ and $820^{\circ} \mathrm{C}$, Figure $10 \mathrm{~h}$, i show that the grain boundaries migrate, the grains grow rapidly; however, some grains grow abnormally (as shown in the circle), so the uniformity of the crystal grain distribution is reduced.
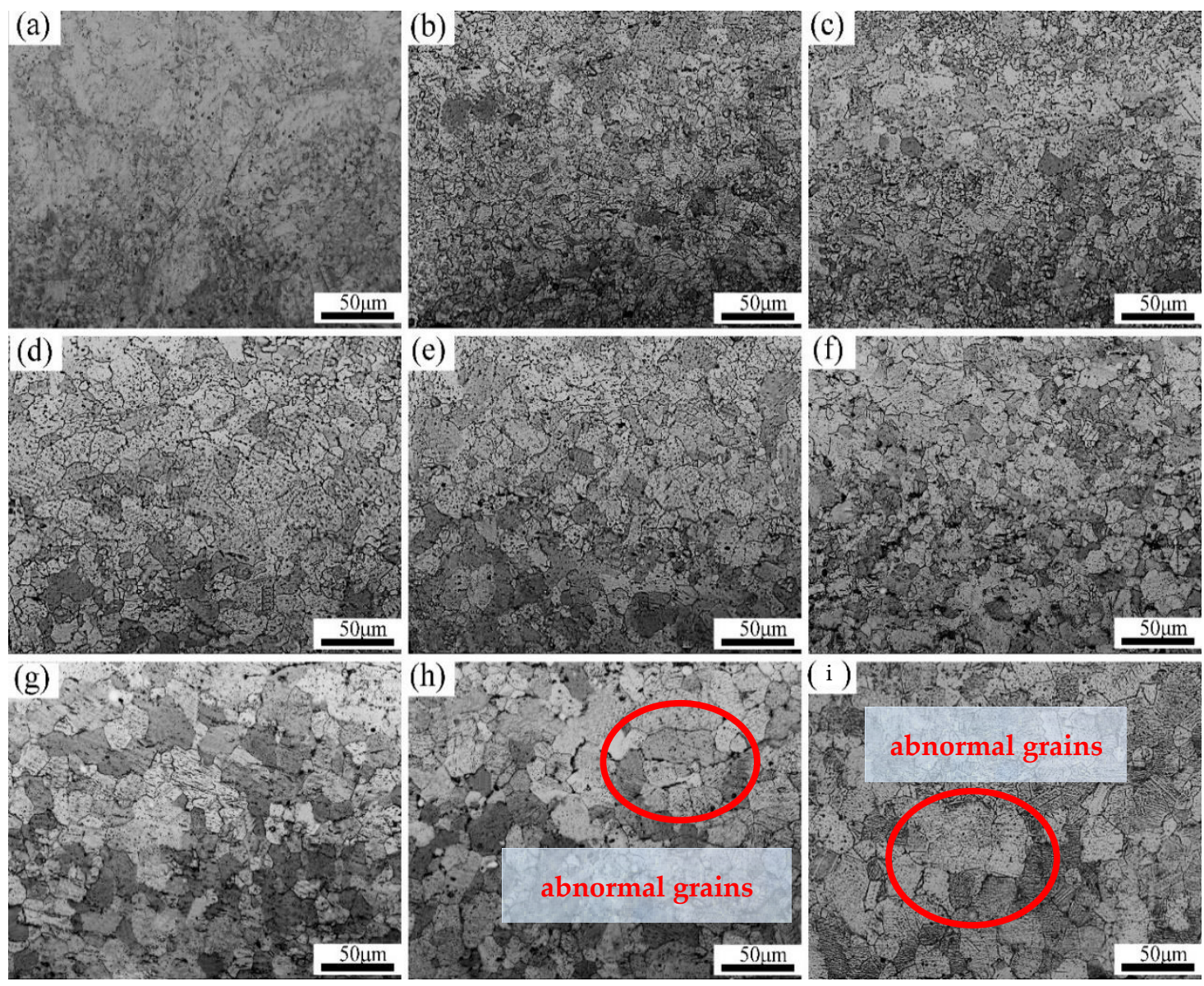

Figure 10. The metallography of $60 \%$ deformation with various annealing temperatures: (a) $460{ }^{\circ} \mathrm{C}$, (b) $500{ }^{\circ} \mathrm{C}$, (c) $540{ }^{\circ} \mathrm{C}$, (d) $620^{\circ} \mathrm{C}$, (e) $660{ }^{\circ} \mathrm{C}$, (f) $700{ }^{\circ} \mathrm{C}$, (g) $740{ }^{\circ} \mathrm{C}$, (h) $780{ }^{\circ} \mathrm{C}$, and (i) $820^{\circ} \mathrm{C}$.

The microhardness and average grain size of Er metal with $60 \%$ deformation after annealing for $1 \mathrm{~h}$ are plotted in Figure 11 and Table 3 . When the annealing temperature increases from $460{ }^{\circ} \mathrm{C}$ to $540{ }^{\circ} \mathrm{C}$, the grain of Er metal grows slowly, and the hardness decreases from $134.47 \mathrm{HV}$ to $98.03 \mathrm{HV}$ rapidly. This is due to the dislocation density 
decreases and the stored energy of microstructure decreases during the recovery and recrystallization process [34,35]. As the annealing temperature increases above $540{ }^{\circ} \mathrm{C}$, the hardness tends to be steady and the average grain size rapidly increases from $5.43 \mu \mathrm{m}$ at $540{ }^{\circ} \mathrm{C}$ to $21.52 \mu \mathrm{m}$ at $700{ }^{\circ} \mathrm{C}$, which is due to the internal stress disappearing and the energy of annealing completely transforms into grain growth. When the temperature reaches to $740{ }^{\circ} \mathrm{C}$, the hardness is maintained at $97 \mathrm{HV}$ and the crystal grain is $24.53 \mu \mathrm{m}$; then the grain size and hardness tend to be flat, which indicates that the recrystallization is finished at $740{ }^{\circ} \mathrm{C}$. The grain growth trend is the same as that of the rolled copper target [36]. Moreover, the results of hardness and grain size changes at different annealing temperatures are consistent with the results of microstructure changes in Figure 10. It is concluded that when the deformation is $60 \%$, a high-quality Er target with fine and uniform grains can be obtained after annealing at $740{ }^{\circ} \mathrm{C} \times 1 \mathrm{~h}$.

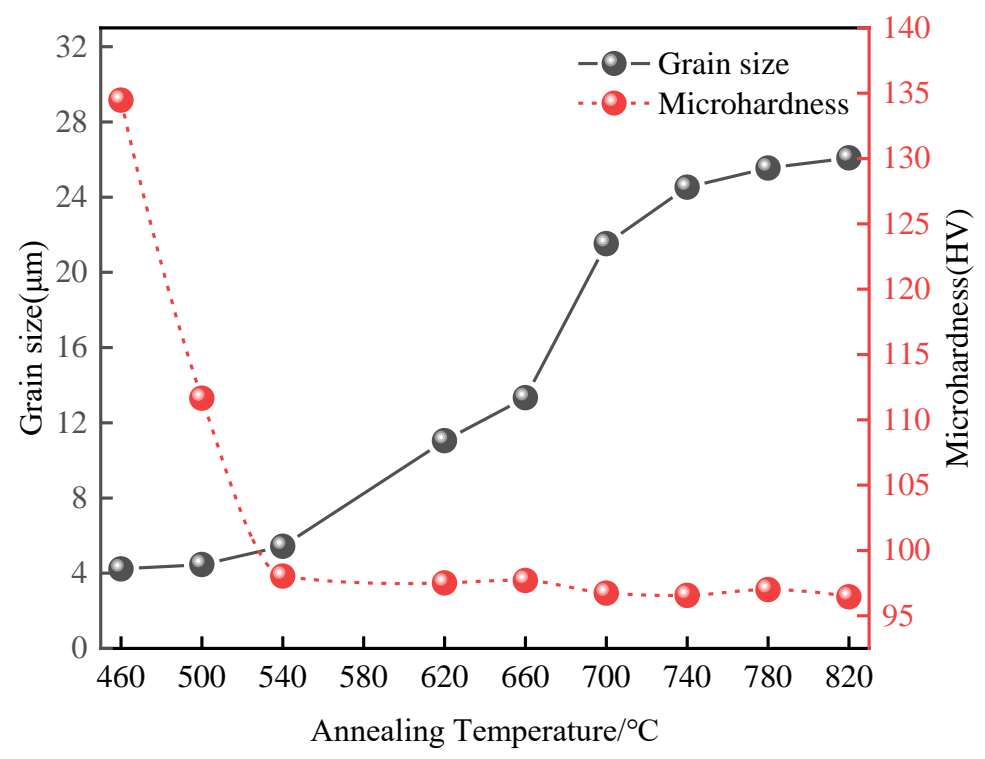

Figure 11. The relationship curve between annealing temperature with grain size and microhardness at $60 \%$ deformation.

Table 3. Hardness and grain size of $60 \%$ deformation at different heat treatment temperatures.

\begin{tabular}{cccccccccc}
\hline Temperature $\left({ }^{\circ} \mathrm{C}\right)$ & 460 & 500 & 540 & 620 & 660 & 700 & 740 & 780 & 820 \\
Microhardness $(\mathrm{HV})$ & 134.47 & 111.65 & 98.03 & 97.51 & 97.70 & 96.73 & 96.55 & 97.00 & 96.45 \\
Grain size $(\mu \mathrm{m})$ & 4.23 & 4.46 & 5.43 & 11.05 & 13.33 & 21.52 & 24.53 & 25.55 & 26.09 \\
\hline
\end{tabular}

\section{Conclusions}

In this study, the effect of cold rolling and annealing temperature on grain size, grain uniformity, and texture of Er metal were investigated. The main experimental conclusions were summarized as follows:

(1) The grains of Er metal are gradually broken and refined with increasing deformation. When the deformation reaches to $60 \%$, the grains are dominated by fine deformed structures, the average grain size is $3.37 \mu \mathrm{m}$, and the crystal orientation distribution is uniform;

(2) The deformation mechanism is transformed from the synergistic way of twinning and slip to the slip-dominated deformation at greater than $40 \%$ deformation and the generation of twins contributes to the formation of (0001) orientation;

(3) Compared with the initial as-cast state, the crystal orientation of (0110) is weakened gradually with increasing deformation; the crystal orientation of $(\overline{12} \overline{10})$ remains unchanged in the beginning deformation stage, then gradually become weakened as the deformation 
is increased beyond $50 \%$. The preferred orientation of the $(1110)$ is obvious, and there is a tendency to further strengthen;

(4) For the $60 \%$ cold rolling deformation of Er metal, the deformed microstructure was replaced by fine equiaxed grains as the annealing temperature increased. The average grain size is $24.53 \mu \mathrm{m}$ and the grain size distribution is uniform after the optimal annealing process of $740{ }^{\circ} \mathrm{C} \times 1 \mathrm{~h}$.

Author Contributions: Conceptualization, S.C. and X.Z.; methodology, D.W.; software, S.W.; validation, S.C., M.X., and W.L.; formal analysis, D.C., W.Y., and N.M.; investigation, S.C.; resources, Z.W. and D.C.; data curation, S.C. and Y.W.; Writing-original draft preparation, S.C., X.Z., and Z.L.; Writing-review and editing, S.C. and X.Z.; visualization, W.Y. and J.L.; supervision, Z.L.; project administration, D.W.; funding acquisition, X.Z. All authors have read and agreed to the published version of the manuscript.

Funding: This study was financially supported by the National Key Research and Development Program of China (No.2017YFB0405901) and Research on zone melting and purification technology of high-purity metal lanthanum for new storage (No.6010101).

Institutional Review Board Statement: Not applicable.

Informed Consent Statement: Not applicable.

Data Availability Statement: The data that supports the results of this study are available upon request from the authors.

Conflicts of Interest: The authors declare no conflict of interest.

\section{References}

1. Li, W.; Zhou, J.; Cai, S.; Yu, Z.; Zhang, J.; Fang, N.; Li, T.; Wu, Y.; Chen, T.; Xie, X.; et al. Uniform and ultrathin high-K gate dielectrics for two-dimensional electronic devices. Nat. Electron. 2019, 2, 563-571. [CrossRef]

2. Losurdo, M.; Giangregorio, M.M.; Bruno, G.; Yang, D.; Irene, E.A.; Suvorova, A.A.; Saunders, M. $\operatorname{Er}_{2} \mathrm{O}_{3}$ as a high-K dielectric candidate. Appl. Phys. Lett. 2007, 91, 013502. [CrossRef]

3. Miritello, M.; Lo Savio, R.; Piro, A.M.; Franzò, G.; Priolo, F.; Iacona, F.; Bongiorno, C. Optical and structural properties of Er ${ }_{2} \mathrm{O}_{3}$ films grown by magnetron sputtering. J. Appl. Phys. 2006, 100, 013502. [CrossRef]

4. Pan, T.M.; Chen, C.L.; Wen, W.Y.; Hbu, S.J. Structural and electrical characteristics of thin erbium oxide gate dielectrics. Appl. Phys. Lett. 2006, 89, F29. [CrossRef]

5. Yao, Z.; Suzuki, A.; Levchuk, D.; Chikada, T.; Tanaka, T.; Muroga, T.; Terai, T. Hydrogen Permeation through Steel Coated with Erbium Oxide by Sol-Gel Method. J. Nucl. Mater. 2009, 386, 700-702. [CrossRef]

6. Mao, W.; Fujita, M.; Chikada, T.; Yamaguchi, K.; Suzuki, A.; Terai, T.; Matsuzaki, H. Growth of Single-Phase Nanostructured $\mathrm{Er}_{2} \mathrm{O}_{3}$ Thin Films On Si (100) by Ion Beam Sputter Deposition. Surface Coat. Technol. 2015, 283, 241-246. [CrossRef]

7. Shen, H.H.; Peng, S.M.; Long, X.G.; Zhou, X.S.; Yang, L.; Zu, X.T. The effect of substrate temperature on the oxidation behavior of erbium thick films. Vacuum 2012, 86, 1097-1101. [CrossRef]

8. Fu, Z.B.; Wang, C.Y.; Li, C.Y.; Zhang, H.Q.; Yang, X.; Xu, H. Factors influencing fabrication of erbium hydride films used as targets to generate high energy proton beams. High Power Laser Part. Beams 2011, 23, 2090-2092.

9. Zhang, Q.F.; Yi, Y.; Luo, J.S. Effect of sputtering power on microstructure of Er thin films deposited by magnetron sputtering. Vaccum 2020, 57, 17-20.

10. Dixit, N.; Xie, K.Y.; Hemker, K.J.; Ramesh, K.T. Microstructural evolution of pure magnesium under high strain rate loading. Acta Mater. 2015, 87, 56-67. [CrossRef]

11. Jannotti, P.A.; Lorenzo, N.J.; Walter, T.R.; Schuster, B.E.; Lloyd, J.T. Role of Anisotropy in the Ballistic Response of Rolled Magnesium. Mech. Mater. 2021, 160, 103953. [CrossRef]

12. Sabat, R.K.; Sahoo, S.K.; Panda, D.; Mohanty, U.K.; Suwas, S. Orientation Dependent Recrystallization Mechanism During Static Annealing of Pure Magnesium. Mater. Charact. 2017, 132, 388-396. [CrossRef]

13. Pinc, J. Thermoactivated Dislocation Motion in Rolled and Extruded Magnesium: Data of the Low-Temperature Acoustic Experiment. Metals 2021, 11, 1647.

14. Biswas, S.; Singh, D.S.; Beausir, B.; Toth, L.S.; Suwas, S. Thermal response on the microstructure and texture of ECAP and cold-rolled pure magnesium. Metall. Mater. Trans. A 2015, 46, 2598-2613. [CrossRef]

15. Majchrowicz, K.; Jozwik, P.; Chrominski, W.; Adamczyk-Cieslak, B.; Pakiela, Z. Microstructure, Texture and Mechanical Properties of Mg-6Sn Alloy Processed by Differential Speed Rolling. Materials 2021, 14, 83. [CrossRef]

16. Zhao, X.H.; Liu, K.C.; Xu, D.S.; Liu, Y.; Hu, C.H. Effects of Ultrasonic Surface Rolling Processing and Subsequent Recovery Treatment On the Wear Resistance of Az91D Mg Alloy. Materials 2020, 13, 5705. [CrossRef] 
17. Won, J.W.; Lee, T.; Hong, S.; Lee, Y.; Lee, J.H.; Lee, C.S. Role of deformation twins in static recrystallization kinetics of high-purity alpha titanium. Met. Mater. Int. 2016, 22, 1041-1048. [CrossRef]

18. Kumar, M.A.; Wroński, M.; Mccabe, R.J.; Capolungo, L.; Wierzbanowski, K.; Tomé, C.N. Role of Microstructure On Twin Nucleation and Growth in Hcp Titanium: A Statistical Study. Acta Mater. 2018, 148, 123-132. [CrossRef]

19. Yang, Z.; Yu, W.; Lang, S.; Wei, J.; Ding, P. Hot Deformation Behavior and Processing Maps of a New Ti-6Al-2Nb-2Zr-0.4B Titanium Alloy. Materials 2021, 14, 2456. [CrossRef]

20. Liu, X.; Yu, D.; Fan, Q.; Shi, R. Influence of hot rolling and heat treatment on the microstructural evolution of $\beta 20 \mathrm{C}$ titanium alloy Materials 2017, 10, 1071. [CrossRef]

21. Xu, X.; Dong, L.M.; Ba, H.B.; Zhang, Z.Q.; Yang, R. Hot Deformation Behavior and Microstructural Evolution of Beta C Titanium Alloy in B Phase Field. Trans. Nonferrous Metal. Soc. 2016, 26, 2874-2882. [CrossRef]

22. Huang, P.; Huang, M.S.; Fan, Y.C.; Liu, H.; Zhang, W.Y.; Liu, W. Annealing process of high purity scandium metal. Heat Treat. Met. 2020, 45, 83-85.

23. Wang, S.; Wu, D.; Zhong, J.; Chen, D.; Li, Z.; Wang, Z.; Pang, S. Effect of annealing on the microstructure and mechanical properties of high purity erbium metal. Mater. Res. Express 2021, 8, 046510. [CrossRef]

24. Taskaev, S.; Skokov, K.; Karpenkov, D.; Khovaylo, V.; Ulyanov, M.; Bataev, D.; Dyakonov, A.; Gutfleisch, O. Influence of severe plastic deformation on magnetocaloric effect of dysprosium. J. Magn. Magn. Mater. 2019, 479, 307-311. [CrossRef]

25. Taskaev, S.; Skokov, K.; Khovaylo, V.; Buchelnikov, V.; Pellenen, A.; Karpenkov, D.; Ulyanov, M.; Bataev, D.; Usenko, A.; Lyange, M.; et al. Effect of severe plastic deformation on the specific heat and magnetic properties of cold rolled Gd sheets. J. Appl. Phys. 2015, 117, 123914. [CrossRef]

26. Taskaev, S.; Skokov, K.; Khovaylo, V.; Karpenkov, D.; Ulyanov, M.; Bataev, D.; Dyakonov, A.; Gutfleisch, O. Effects of severe plastic deformation on the magnetic properties of terbium. Aip Adv. 2018, 8, 048103. [CrossRef]

27. Taskaev, S.V.; Buchelnikov, V.D.; Pellenen, A.P.; Kuz'Min, M.D.; Skokov, K.P.; Karpenkov, D.Y.; Bataev, D.S.; Gutfleisch, O. Influence of thermal treatment on magnetocaloric properties of Gd cold rolled ribbons. J. Appl. Phys. 2013, 113, 17A933. [CrossRef]

28. Ren, Y.; Zhang, X.; Xia, T.; Sun, Q.; Liu, Q. Microstructural and textural evolution of high-purity titanium under dynamic loading. Mater. Des. 2017, 126, 123-134. [CrossRef]

29. Liu, N.; Wang, Y.; Wei-Jun, H.E.; Jun, L.I.; Liu, Q. Microstructure and Textural Evolution During Cold Rolling and Annealing of Commercially Pure Titanium Sheet. Trans. Nonferrous Metal. Soc. 2018, 28, 1123-1131. [CrossRef]

30. Yu, H.; Wang, L.; Chai, L.; Li, J.; Lu, C.; Godbole, A.; Wang, H.; Kong, C. High Thermal Stability and Excellent Mechanical Properties of Ultrafine-Grained High-Purity Copper Sheets Subjected to Asymmetric Cryorolling. Mater. Charact. 2019, 153, 34-45. [CrossRef]

31. Chen, C.T.; Song, Y.C.; Yu, G.P.; Huang, J.H. Microstructure and hardness of hollow cathode discharge ion-plated titanium nitride film. J. Mater. Eng. Perform. 1998, 7, 324-328. [CrossRef]

32. Cunningham, N.; Lefèvre, M.; Dodelet, J.; Thomas, Y.; Pelletier, S. Structural and mechanical characterization of as-compacted powder mixtures of graphite and phenolic resin. Carbon 2005, 43, 3054-3066. [CrossRef]

33. Sun, H.C.; Li, S.K.; Yu, X.D.; Tan, C.; Wang, F.C. Research on texture and mechanical performance of high purity CVD tungsten Rare Metal Mat. Eng. 2010, 39, 1415-1418.

34. Fu, X.; Wang, R.; Zhu, Q.; Wang, P.; Zuo, Y. Effect of annealing on the interface and mechanical properties of Cu-Al-Cu laminated composite prepared with cold rolling. Materials 2020, 13, 369. [CrossRef] [PubMed]

35. Zareian, Z.; Emamy, M.; Malekan, M.; Mirzadeh, H.; Kim, W.J.; Bahmani, A. Tailoring the mechanical properties of Mg-Zn magnesium alloy by calcium addition and hot extrusion process. Mater. Sci. Eng. A 2020, 774, 138929. [CrossRef]

36. Zeng, X.; He, J.J.; Jiang, X.; Zeng, H.; Wan, X.Y.; Shang, Z.Y. Research On Grain Refinement Process and Microstructure of Ultra-High Purity Copper Used for Integrated Circuit. Mater. Sci. Forum 2016, 852 Pt 1, 601-606. [CrossRef] 